\begin{abstract}
Александр Марков
Российский государственный гуманитарный университет markovius@gmail.com
\end{abstract}

Alexander Markov

Russian State University for the Humanities

markovius@gmail.com

\title{
СОДЕРЖАТЕЛЬНОСТЬ СМЕНЫ МЕДИЙНОЙ ФОРМЫ В ПАРОДИЙНОМ РОМАНЕ ПАВЛА АССА И НЕСТОРА БЕГЕМОТОВА ШТИРЛИЦ, ИЛИ КАК РАЗМНОЖАЮТСЯ ЕЖИКИ
}

\section{THE CONTENT EFFECT OF THE CHANGE OF THE MEDIA FORM IN THE PARODY NOVEL BY PAVEL ASS AND NESTOR BEGEMOTOV STIRLITS, OR HOW THE HEDGEHOGS BREED}

В данной на примере пародийного цикла романов о Штирлице Павла Асса и Нестора Бегемотова показывается, как переход от машинописного и типографского набора к компьютерному бытованию текстов менял содержательные предпочтения читателей. Обосновывается гипотеза, что компьютерный оборот текстов оспорил механизмы производства текстов как в официальной литературе, так и в Самиздате. Официальная система производства текстов подразумевала не только цензуру и самоцензуру, но и определенное представление о высокой степени всеведения автора, который благодаря доступу как к устным, так и письменным текстам, и может внушить читателю мысль об однозначно добрых намерениях героя. В пародийных романах о Штирлице, которые стали бестселлерами в 1988-1994 году, тематизировалась специфика компьютерной кодировки и доступности информации, способствуя превращению пользования компьютерами из маргинальной практики в предмет общего интереса.

Ключевые слова: интермедиальность, цифровой набор, цифровое бытование текста, цензура, Самиздат, социология массового чтения, Отто фон Штирлиц (Максим Исаев).

In this article, using the example of a parody cycle of the novels about Stirlitz by Pavel Ass and Nestor Begemotov, it is shown how the transition from typewritten and typographic typesetting to computer use of texts changed the content preferences of the readers. The hypothesis is substantiated that the computer circulation of texts challenged the mechanisms of text production both in the official literature and in samizdat. The official system of text production implied not only censorship and self-censorship, but also a certain idea of a high degree of omniscience of the author, which, thanks to access to both oral and written texts, can inspire the reader with the idea of the hero's unam- 
biguously good intentions. The parody novels about Stirlitz, which became bestsellers in 1988-1994, focused on the specifics of computer coding and the availability of information, contributing to the transformation of using computers from a marginal practice into a subject of general interest.

Key words: intermediality, digital typing, digital form of the text, censorship, samizdat, sociology of mass reading, Otto von Stirlitz (Maksim Isaev).

Любой историк литературы может назвать примеры, как переход к другому медиуму производства и бытования текстов влиял и на их содержание, и на их массовый успех. Достаточно вспомнить общеизвестные события из истории культуры как связь успешного распространения христианства со сменой формы книги от свитка к кодексу, что позволяло быстро сопоставлять различные места из Библии и тем самым доказывать, что библейская история исполняется прямо здесь и сейчас, поддерживая эсхатологическую и жизненную программу христианства. Другой пример - публикация Лютером своих тезисов как печатных: хотя публиковать рукописные тезисы перед богословским диспутом было нормой его времени, но печатная форма создавала потенциально неограниченное количество читателей, а значит, и свободное распространение позиции Лютера как уже кодифицированной. До сих пор за триумфом многих бестселлеров хотя бы отчасти стоит выбор медийной формы, включая способ набора, способ работы типографий, каналы распространения и одновременного появления в продаже в разных местах. Так, доля успеха серии романов о Гарри Поттере Дж. Роулинг вполне может быть обязана употреблению гарнитуры гарамон, которую ввел Анри Этьенн для публикации Нового Завета в 1550 году в массовом издании, разбитым на стихи и с комментариями, что и сделало Писание домашним, а не только храмовым чтением, во Франции.

Рассматриваемый сюжет ни разу не привлекал внимания историков Самиздата, но также оказался вне области интересов и историков Рунета. Его ближайшая рамка - технический прогресс в СССР 1980-х годов, который и позволял использовать компьютеры, а не только пишущие машинки, для свободного распространения текстов. Сравнительная скудость технической базы, а именно, доступность компьютеров с достаточным функционалом только в ведущих учреждениях, нивелировала различия между самими способами распространения, был ли это принцип Bulletin Board System, с передачей необходимого текста по модему, или же принцип DiscMag, электронного зина, с записью необходимого содержания на дискету. Высокая стоимость и медленная работа принтеров делала символом свободного распространения текстов не устройство для печати, а фотокопирование машинописного набора, и символом перестроечной свободы информации стал «Ксерокс», копировальная машина. Для свободного распространения текстов не требовалось специальных знаний и доступа к наборной технике: текст, набранный на до- 
машней пишущей машинке, мог быть легко размножен, и поэтому фотокопирование и право любого автора на свободу выражения оказались тесно связаны. А профессиональный набор на компьютерной технике воспринимался как принадлежность только издательской или институционализированной сферы где-то до середины 1990-х годов, когда персональные компьютеры стали доступны среднему классу, а пользовательски ориентированное программное обеспечение позволило пользоваться ими без специальной подготовки. Тем более важным оказывается исследование произведений, созданных с помощью компьютерного набора как некоторая техническая и идейная новация перестроечного времени, как сенсация, и мы попытаемся на репрезентативном примере выяснить, как связаны медийная и содержательная сенсационность.

Наша базовая гипотеза состоит в том, что отсутствие спецификации распространения компьютерного набора - пересылка по электронным сетям, распечатка на принтере тиража, ксерокопирование разовой распечатки на принтере или пользование услугами офсетных типографий - превращало сам факт последовательного компьютерного набора какого-то литературного проекта с принципиальным игнорированием норм издательской (предпечатной) подготовки текстов, в медийную революцию, вызывающую повышенное внимание читателей. Такое нарастающее внимание могло создаваться сознательным игнорированием процедур учета того, как текст будет выглядеть типографски, уже на этапе создания текста: примером может служить труд Дмитрия Галковского Бесконечный тупик (1988), представляющий собой древовидное (фрактальное) повествование с элементами гипертекста. Лучшим способом его бытования было бы сетевое, но его сначала отрывочная, а потом полная публикация в постсоветское время (1992-1997) заставили воспринимать его в среде молодых читателей как новый способ существования литературы как таковой, как метакритику литературности и одновременно как сенсационный способ организации мышления, без предварительной его адаптации к ожиданиям редактора, издателя и подразумеваемого ими читательского круга.

Другой пример - составленный Львом Рубинштейном альманах Личное дело (1991), представивший довольно широкому читателю поэзию Самиздата - оформление обложки и титульного листа отсылало к папкам бюрократического пользования и одновременно к машинописному набору - тем самым, вслед за эмансипацией машинописи в Самиздате, от бюрократического мира к свободному обороту информации, произошла и эмансипация самих бюрократических практик, которые оказались практиками громкой легитимации прежде неизвестной широкому кругу читателей литературы. Сходная игра с формами официального распространения в других искусствах из-за другой специфики цензуры происходила еще раньше, в застойное время, и чтобы не обращаться к сложной истории визуальных искусств, приведем только пример 
из истории музыки: опубликованные в 1968 г. под именем барочных авторов произведения композитора Владимира Вавилова были для него единственным способом публикации, обходящим как тематическую цензуру (религиозное или придворное содержание мелодий), так и формально-административную (Вавилов не был членом Союза Композиторов и не имел права на публикацию собственных произведений). Хотя любому знатоку барочной музыки было понятно, что опубликованные и исполненные Вавиловым музыкальные пьесы, с явными приемами вальса, джаза и рока, не могли быть созданы в эпоху барокко, - само молчание специалистов вместе с интуитивными догадками слушателей, что перед ними нечто инновационное в сравнении и со старой, и с советской музыкой, сделало эти произведения музыкальными бестселлерами и обеспечило им устойчивое исполнение в мире. В литературе, как мы увидим ближе к концу статьи, тоже были предвестия такой медийной революции, которая и произошла в перестроечное время, но для их появления требовалась более сложная конфигурация самих книгоиздательских обычаев и ряд счастливых совпадений.

Выбранный для исследования пример, роман Павла Асса и Нестора Бегемотова (псевдонимы) Штирлии, или как размножаются ёжики (Acc, Бегемотов: http) (здесь и далее цитируется по авторизованной версии), был написал в 1986-1987 году на доступной этим авторам, техническим специалистам, компьютерной технике. Технические специалисты, имея доступ к новому оборудованию, могли программировать, создавать игры, но также создавать на досуге художественные произведения. В этом примере поражает широта распространения, на первой взгляд противоречащая любительскому характеру самого сочинения: учесть все тиражи этого произведения в начале 1990-х невозможно, так как ряд изданий были неофициальными и без реального учета отпечатанных экземпляров, его распространение сопоставимо с распространением прототипа - романа Юлиана Семенова Семнадияать мгновений весны (1969). Мы исходим из того, что популярность этого фанфика была обусловлена не столько известностью названного прототипа, особенно снятого по книге одноименного телевизионного сериала Т. Лионзовой 1973 г., ставшего источником большой массы советских анекдотов и одним из символов телевидения брежневской эпохи в массовом сознании, - сколько той медийной революцией, к которой относился способ производства этого произведения. В перспективе полученные выводы можно будет применить к причинам популярности, краткой или не очень краткой, других бестселлеров, употребивших серийную технику при нарочито любительском литературном письме, как, например, произведения Паоло Коэльо, Оксаны Робски или Эрики Л. Джеймс.

В исследовании мы опираемся на ключевой вывод специалиста по постфольклору А. С. Архиповой, показавшей, что анекдоты о Штирлице строятся вопреки многим правилам такой постфольклорной формы 
как анекдот, опираясь на маргинальные медийные особенности телевизионного сериала «Семнадцать мгновений весны», прежде всего, закадровый голос диктора, который способен проникать в мысли Штирлица и при этом воспроизводит правильную точку зрения на Штирлица, правильный идеологический нарратив о нем. Соответственно верная кодировка в широком семиотическом смысле, правильно устроенный русский литературный язык, и связывает проникновенность в передаче героя на экране, режимы его рассказанной мысли как режимы зрительской эмпатии, с нормой идеологического понимания этого героя (Архипова 2013: 33-40). На то, что идеологический закадровый голос формирует зрителя-простака, велит зрителю быть простаком, обратил внимание еще А. Ф. Белоусов (Белоусов 1995: 17). Тогда анекдот, согласно выводам Архиповой, показывает внутренние непредсказуемые противоречия этой кодировки, ее с самого начала временную деформированность, например, разрыв между экранным эффектом присутствия и летописного типа повествованием в прошедшем времени (Там же: 44), и доводя до абсурда правильный «дикторский» язык, разменивая его на каламбуры, подрывает авторитетное высказывание власти.

При этом Архипова подчеркивала, что наступление Интернет-эпохи почти не повлияло на семантику и прагматику анекдотов, так как анекдоты эволюционируют по собственным законам (Там же: 26) - позиция Архиповой здесь сознательно близка теории эволюционных мемов Р. Докинза, повлиявшей, как известно, и на метаописания сетевого постфольклора как системы «мемов». Утверждения Архиповой о подрыве авторитетной интонации совпадают с выводами М. Эпштейна, что сама форма анекдотов про Штирлица игнорирует различие между до-постмодернистским и постмодернистским использованием речи: Эпштейн приводит в качестве иллюстрации анекдот о встрече Штирлица с Бодрийяром, полностью соответствующий стандартной поэтике анекдотов про Штирлица (Эпштейн 2019: 112). Заметим, что в российском интернет-фольклоpe, как показывают данные сетевого поиска, Штирлиц так же успешно встречается с известнейшим создателем и летописцем Рунета Антоном Носиком. Мы рассматриваем в этой статье случай литературной рецепции темы Штирлица, как мы увидим, сознательно дистанцированной от анекдота именно для того, чтобы переход от книжной индустрии и индустрии самиздата и интеллигентского фольклора (Дмитриев 1995) к компьютерному бытованию текстов был, наоборот, заметным и привлекающим новую публику.

Проект Асса и Бегемотова, как уже было сказано выше, был проектом любительского письма, который включал в себя сиквельl, сnин-оффpbl и кроссоверы, а также фанфики других авторов. Так, спин-оффом романа следует признать роман Импотент (издательство МИК, 1994, серия имела общее название «Библиотека пародии и юмора» и выходила до 1995 года), где действует Швацц-младший, сын одного из главных 
героев романа про ежиков, и где пародируются штампы бондианы и эротического триллера. А кроссовером следует считать некоторые из последующих романов в этой серии о Штирлице, написанные и с участием других авторов, где он начинает в дивизии Чапаева и герои фильма и анекдотов про Чапаева выступают учителями для Штирлица — кроме пародии на фильм, здесь обыграны штампы из фильмов про ниндзей и других мастеров боевых искусств, где обязательно есть учитель, первые испытания и принципиальный подрыв любовной линии, невозможной для героя. Здесь авторы предвосхитили, конечно, мир романа Виктора Пелевина Чапаев и Пустота (1996), где соединение советского чапаевского мифа и буддистской философии оспаривало идеологический авторитет прежних форм не только художественного, но и документального повествования, вообще достоверности в выстраивании сюжетных линий.

В других книгах серии, созданных уже после распада СССР, есть указания и на деятельность Штирлица и его потомков в перестроечное и послеперестроечное время, одна из них завершается встречей Ельцина с авторами, описанной в духе слэшеров, что уже можно считать вариантом фанфика, причем созданного той же группой авторов - сближение условного мира фантазийного произведения с волнующими читателей здесь и сейчас событиями. Кроме того, Асс и Бегемотов выступили как издатели для своих предшественников, издав в том же оформлении, что и свою серию в издательстве МИК, избранные малоизвестные произведения И. Ильфа и Е. Петрова, тем самым указав, что маргинальные практики классиков советского юмора, далекие от тиражно более успешных, но и невольно более деформированных цензурой и самоцензурой Двенадиати стульев и Золотого теленка, но сближающиеся с анекдотом по критерию непосредственности авторского выражения, могут при свободном распространении быть восприняты как вклад в утверждение этой новой медийности, где власть редактора сменяется авторитетом технического специалиста издательства нового типа.

В этой же серии был выпущен и сборник постфольклора позднесоветского времени, включивший в себя так называемые садистские стишки и анекдоты, как один из ключевых жанров позднесоветского подрыва властных дискурсов, в частности, инструкций по технике безопасности, обсцённую пародию на роман в стихах А. С. Пушкина Евгений Онегин, оспаривавшую школьную норму разговора о классике, и ряд других произведений, объединенных только маргинальным характером внутри постфольклора, характером школьной пародии, — что сразу вербовало в читатели серии вчерашних и даже сегодняшних школьников. В этой же серии, как мы сказали, выходили пародии-кроссоверы на холмсиану, бондиану и другие явления массовой культуры, отсылавшие одновременно к советской рецепции этих сюжетов, циклу телефильмов о Шерлоке Холмсе Игоря Масленникова (1979-1986), и к боевикам и бон- 
диане видеосалонов (массового видеопроката) начала 1990-х - советский и постсоветский зрительский опыт (как и опыт читателей советской литературы и опыт читателей самиздата) оказывались одинаково обесценены в сравнении с новыми возможностями комбинировать сюжеты благодаря свободной издательской политике и свободе издавать что угодно как угодно.

Сюжет романа таков: в руководстве Рейха Борман выступает как трикстер, в том числе любит подкладывать кнопки на стул и Штирлицу, и другим коллегам; но только Штирлиц распознает будущие проделки Бормана, и его за это очень уважают, он по сути только и может остановить это трикстерство. Мюллер действует противоположным образом: он фактический организатор биржевых взаимодействий, таких как обмен секретаршами, - при этом если Борман как банальный трикстер и развратник легко может продешевить, то Мюллер как педантичный коллекционер знает всему цену. В такой симметрии героев, подрывающих политики тела друг друга, нетрудно увидеть обыгрывание хиазма, который давно уже отмечен как основной прием, организующий анекдоты о Штирлице (Александрова 2014: 528). Но опять же только Штирлиц в этом как бы преферансе и покере германских персонажей может выступить как некий предел их действий, всякий раз останавливая их и примиряя, за что его не просто ценят, а переоценивают, так что он в романе действует не просто открыто, а со всей возможной дерзостью и преодолением границ, благодаря чему его шпионская миссия и удается. В этом, вероятно, главный секрет успеха этого пародийного фанфика - удача миссии специалиста, который уже не связан с прежними цензурируемыми режимами телесности, совпадает с новой миссией свободного книгоиздания, не связанного ни с книжной спекуляцией, ни с неожиданным трикстерством пропущенных цензурой дефицитных изданий доперестроечных времен.

По ходу действия, наполненного разными комедийными сценами в кабаках и канцеляриях, выписанных вполне в традициях межвоенного германского кабаре, выясняется, что главной проблемой Германии является умение русских партизан подкладывать ежиков на стулья командующим, из-за чего, например, фон Клюге был ранен и не смог правильно отдавать приказы на Курской дуге. Гиммлер предлагает фюреру провести операцию по уничтожению всех ежиков на оккупированной части CССР. При этом фюрер, будучи импотентом, понимает, что он, не имея достаточного сексуального опыта, не может оценить и способность ежиков размножаться, а значит, и правильно оценить успех готовящейся операции. Штирлиц решает сорвать эту операцию сначала символически, вербуя гиперсексуального пастора Шлага, потом вступая в прямую словесную дуэль и с Мюллером, и с Борманом, выведывая всякий раз, как размножаются ежики, и тем самым как бы пытаясь сбить запущенный алгоритм уничтожения ежиков. Таким образом, Штирлиц оказыва- 
ется техническим специалистом, изучающим, как работают узлы разных систем, связанных с размножением, тиражированием, и как бы представляет новый тип перестроечного независимого книгоиздания, которое противостоит тем системным ограничениям старых издательств, которые могут обладать частными умениями (например, высоким уровнем редакционной подготовки), но не могут противостоять трикстерскому появлению систем размножения рукописей новыми подручными средствами.

Но дело в том, что Штирлиц как специалист по информации как раз допустил провал, связанный с межъязыковыми кодировками, если их читать исходя из прежних читательско-телесных привычек: он не узнал в названии операции «Игельс» указание на ежиков. Тут юмор двойной, показывающий ограничения новой издательской сферы, связанной со свободным использованием компьютеров, где сбои кодировки, вплоть до конца 1990-х, например, в словах с ударением случались регулярно: множественное число от der Igel по-немецки будет die Igel, без добавления окончания множественного числа, тем более английского, кроме того, Igel это и еж, и ежик, уменьшительные формы от этого слова в немецком встречаются редко. Не распознав, что операция уже идет, Штирлиц оказался вынужден перейти к решительным действиям и встать на пути эшелона, депортирующего ежиков. Получается, что фактически нужно перезагрузить систему, тогда ежики разбегутся и Рейх потерпит поражение. Тем самым, пародируется каноническая для мировых компьютерных систем кодировка с ее алгоритмами, ориентированными на латиницу, и показывается, что все и грамматические правила языка, грамматическая телесность, поддерживаемая практиками контроля, могут быть оспорены новой медийностью, где всё определяется включением и выключением кнопки компьютера, и можно одной кнопкой запустить хорошо работающую издательскую систему. Иначе говоря, читателю внушается, что овладеть компьютерными премудростями несложно, и читая такие романы, он овладеет быстро компьютером, не боясь его грамматически-программной сложности и отказавшись от прежних косных привычек своего тела, что, конечно, радовало многих читателей, мечтавших о компьютерах именно как о безупречно работающих, хотя и не всегда сразу слушающихся машинах.

Две самые комичные и подробные сцены романа - действия Штирлица на футбольном матче, где он выбегает на футбольное поле, сам забивает голы и наводит порядок, и Штирлиц в психиатрической клинике, где его находит фюрер, - конечно, всеми своими подробностями напоминают о лучших советских сатирах Л. Лагина, М. Булгакова, И. Ильфа и Е. Петрова: старик Хоттабыч на матче, Иван Бездомный в психушке (а в фильме Л. Гайдая по пьесе М. Булгакова Иван Васильевич - и сам Иван Грозный и его двойник), драка Остапа Бендера с шахматистами в Васюках, где комическим оказывается всякий раз персонаж, 
вроде бы владевший всеми навыками убеждения, всеми регистрами правильно выстроенной речи и правильного жеста (Рябова 2015: 57). Оказывается при этом, что отсутствие специальных знаний не позволяет этому персонажу вполне осуществить свою речевую программу (Арустамова, Марков 2016: 116). Апофеоз этого провала дилетанта в советской сатире, например, тот телефон, который Хоттабыч создал как дворцовый артефакт, а не как прибор для связи; филолог, поэт и переводчик Г. Дашевский (Степанова 2014: 36) справедливо сопоставил это действие с работой переводчика в условиях цензуры и самоцензуры, сделавшихся культурной привычкой. Тогда как здесь мысль авторов друга, каковы бы ни были специальные знания, связанные с частными докомпьютерными телесными техниками, невладение навыками статистики, алгоритмами, позволяющими выстроить статистическую модель размножения ежиков, приведет к проигрышу. Злодеи Рейха могут владеть большим количеством отдельных специальных знаний, но они бессильны против Штирлица как своеобразного героя с открытым кодом, который себя раскрыл, но именно этим показал безупречность пользовательского отношения к компьютерам. С другой стороны, Штирлиц может действовать как дилетант, и не терпеть поражение, потому что он не работает в условиях цензуры и самоцензуры вместе с авторами фанфика о нем, и здесь дилетант не терпит поражения, по той же причине, по которой пользователь, научившийся печатать на принтере любое число экземпляров, тоже не знает поражений (во всяком случае, не хочет их знать). Тем самым, такая история Штирлица объясняла советским читателям в непринужденной форме основы информационных технологий и обеспечила этим книгам кратковременный успех, о котором сейчас вспоминают не больше, чем о программировании на компьютерах начала 1990-х.

Итак, сюжет пародийного романа оказывается столь же прост, сколь и далек от обычных анекдотов о Штирлице, где герой оказывается постоянно испытываем эффектами языка, каламбурами, возможными только в русском языке - русские каламбуры гипертрофировали тему ностальгии Штирлица, которая только и позволяет ему совершать подвиги. В романе Асса и Бегемотова нет отсылок непосредственно к анекдотам про Штирлица и к реальной истории того времени. Весь горизонт этого произведения - беллетристика Юлиана Семенова, а на настоящие обстоятельства войны нет даже тени намеков. Межъязыковые каламбуры в романе служат лишь тому, чтобы заставить Штирлица думать только по-русски и, следовательно, не позволить немцам проникнуть в его мысли и замыслы, при том, что по сюжету этой пародии все знают, что Штирлиц - русский шпион. Тем самым, подчеркивается возможность полной локализации информационной системы, а значит, ее пользовательская доступность для всех читателей фанфика. 
Например, на свой день рождения Штирлиц ставит столы на даче буквой Ш, кириллической буквой, а при явлении руководителей Рейха замечает, что все они на букву $Г$ - хотя в немецком часть из них на $\mathrm{H}$, а часть на G. Тем самым, Штирлиц этого романа выстраивает собственный мир в соответствии с навыками кириллической письменности, что было очень важно в эпоху, когда кириллизация компьютеров была локальной, по требованиям отдельных советских ведомств, и вопрос о совместимости кириллической и латинской кодировки не решался. Штирлиц, мысля не просто по-русски, а русскими буквами как бы становится неуязвим для немцев, хотя в этом романе все германские герои знают уже, что он советский шпион, но предпочитают иметь дело с ним, а не, например, с китайским шпионом - подразумевается, что китайская кодировка вообще не будет никому понятна. Это простая мысль - кодировка должна быть не вопросом привилегированного доступа ведомств, а вопросом функционала, позволяющего по-новому решить вопросы о систематизации и типизации больших объемов информации, что было недоступно пишущим машинкам.

Здесь авторы романа о размножении ежиков, поощряя компьютеризацию как главный способ работы с большими объемами данных, подрывают авторитетность не только закадрового голоса в телесериале о Штирлице, но и машинописного самиздата, где проблема кодировки всегда решалась подручными средствами - латиницу можно было вписать от руки или частично имитировать с помощью кириллицы, сбои при этом были редки и выражались разве в исторических анекдотах о невежественных идеологических лекторах, прочитавших тахітит как «тахитит». Тогда как Асс и Бегемотов исследуют ситуацию, когда несовместимость кодировки становится реальной проблемой, но одновременно ресурсом для пересборки литературы на новых издательских основаниях, имея определенные параллели в использовании латиницы в русской пародийной анимации (Спутницкая 2017: 102), заметим, еще со времен мультфильмов-пародий: по сценарию Л. Лагина «Шпионские страсти» (1967) и по сценарию М. Липскерова «Ограбление по...» (1978).

Такая тематизация букв, шрифта и кодировки, в противовес как официальному, так и ведомственному употреблению устаревшей техники, не была изобретением этих авторов, но принадлежит ключевому писателю из ушедших от официального производства текстов в Самиздат - Юрию Домбровскому. В романе Хранитель древностей главный герой, знаток древностей и книг, выступает как гений официально допускаемой культуры, противостоя как вмешательству власти, так и неофициальным попыткам создать нечто вписывающееся в господствующую парадигму. Эта коллизия потом не раз будет обыграна в романах Самиздата, прежде всего, в романах Наследство и Крот истории Владимира Кормера, но интересно, что Домбровский, писавший для печати и опу- 
бликовавший роман достаточным тиражом в 1964 г. (внимание цензуры он привлек только после публикации), как раз обыгрывал тему шрифта, языка и книжной формы. Один из эпизодов романа (Домбровский 1991: 110-111) таков: художник при поддержке директора создает диораму, изображающую суд над Галилеем, тогда как хранитель оспаривает художественную правду такого решения.

Хранитель заявляет, что слишком большие тома у ног Галилея, размер которых требуется перспективистской иллюзией, оказываются одновременно нереалистичными, напоминающими больше подшивку Известий, потому что Галилей не написал бы столько, и также противоречащими контексту диорамы: суд происходит в помещении с цветными окнами, вроде церкви, и тогда поневоле ассоциацией зрителей будет, что Галилей попирает Библию, что неисторично. Хранитель по сути оспаривает власть директора и художника над информационными потоками: директор, читающий Известия и подписывающий тома документов, и художник, которому только и позволено затрагивать церковное и библейское под видом исторической живописи, оказываются такими хозяевами производства информации, мешающими ее настоящему свободному распространению.

Эти образы Домбровский вывел еще в своих новеллах о Шекспире (Там же: 211-212), изобразив там короля и графа как таких же властных людей, учащих Шекспира исторической и фактической достоверности, тогда как Шекспир обладает собственной биографией, которая реализована в его почерке, его изменчивости, и поэтому может подорвать их властно-цензурный авторитет. Тогда как хранитель в романе показывает, как такой официальный оборот информации, наглядно нормированный в диораме, создает противоречивую культуру как таковую. Кроме того, художник задумал дать приписываемое Галилею изречение «А всё-таки она вертится» церковнославянским шрифтом, что как бы делает директора и художника властелинами не только настоящего, но и прошлого, тогда как хранитель убеждает, что такой китч явно неуместен.

Тем самым, противостоит системе подготовки и контроля правильных знаний о прошлом, системе цензуры, и создающей идеологически приемлемую картину, та особая эрудиция хранителя, которая находя неуместность в композиции, вскрывает неполноту этих знаний. Если Шекспир у Домбровского спрятал свои все рукописи и оставил потомкам только криво написанное завещание, чтобы его биография не была присвоения теми, кто создает китчевую историческую достоверность, была можно сказать сбита рукописная кодировка, то хранитель меняет стилизованный шрифт на общепризнанный гражданский, иначе говоря, так высказывается пожелание, чтобы позиция хранителя стала общепризнанной всеми читателями, - а учитывая, что роман сближает хранителя со Христом, а его антагонистов - с Понтием Пилатом, одновременно представителем власти и артистичным ритором в короне-тюрбане 
(Там же: 95), эффект противопоставления общепринятого знания и стилизации еще больше усиливается.

И действительно, роман Домбровского стал первым советским интеллектуальным романом, признанным публикой в таком качестве о такой рецепции подробно рассказал В. Непомнящий в предисловии к цитируемой публикации (Там же: 3-4). Потом эта коллизия свободного распространения кодов для подрыва корпоративной власти была переиграна в романе Ч. Т. Айтматова Плаха (1986), где как раз по ходу действия Христос (полностью скопированный с булгаковского персонажа, без обращения к Евангелиям) сам овладевает всеми ресурсами публицистического высказывания о себе, говоря языком перестроечной газеты и лишая Пилата привилегий публичности, что соответствовало перестроечным упованиям на гласность как главный способ борьбы с бюрократией. В варианте Асса и Бегемотова мы уже видим не перекодировку, а компетентность только культового героя Штирлица в работе с русской кириллической кодировкой, что еще больше усиливает эффект внимания, отождествляя возможность кириллического набора на компьютере с причастностью ажиотажу вокруг чего-то культового и героического в широком смысле.

Такая ситуация тематизации книжной формы была осмыслена С. С. Аверинцевым в Поэтике ранневизантийской литературы (Аверинцев 1977: 212-240), где он обратил внимание на важный топос житий, восходящий, конечно, к процедуре инициации пророка - обжиганию губ и проглатыванию какого-то вещества, а именно, что обучение грамоте может отождествляться с выпиванием самой книги, которая и делает тело святого иным, подвластным аскетическому порядку. Довольно сложная аргументация главы «Слово и книга» в этом труде явно находится за пределами интересов данной статьи, но важен один момент: Аверинцев настаивал на том, что христианское отношение к книге подорвало прежнюю замкнутую античную культуру изящного тела и эффектного риторического жеста, культуру телесной иллюзии, указав на милосердие, глубинное сердечное принятие знания. Благодаря этому сама запись буквами, которая в античности считалась делом раба, раб переписывал и раб зачитывал вслух, стала привилегией христианина, способного напрямую обращаться к Богу и святым с помощью документов, записей, текстов.

Тем самым получалось как у Домбровского, что вместо устной стилизованной импровизации, в которой вдруг открываются некоторая нарочитость и почти китчевость, появляется ценность письма как основного жеста, почти таинства (как Шекспир у Домбровского не хочет доверять свои рукописи перформерам-цензорам), становится возможно создавать драгоценные иллюминированные рукописи. При этом Аверинцев отметил два специфических отличия византийского средневековья от западного: субъектом письма может выступать сам город, Кон- 
стантинополь, «пишущий» гимн Божьей Матери, иначе говоря, круг привилегированный, столичных жителей, но широкий, и что аскетическое понимания чтения и переписывания книг не противоречило любованию ими, практичность рукописи и красота оформления не были разнесены по разным доменам средневековой культуры, например, монастырской и придворной, а могли считаться частью одного «делания». Тем самым, Аверинцев поневоле и создал собственную книгу как ценимую интеллектуалами не только за доступ к почти недоступным сведениям о средневековом богословии, но и за то, что она как бы сама выстраивала этот широкий круг привилегированных интеллектуалов, способных ее понять без сбоя кодировок и инерции отраслевых кодировок.

Итак, позднесоветский опыт тематизации печатного медиа показывал, как идеологические и риторические стратегии, создающие правдоподобие, могут быть подорваны неправдоподобностью, чудесностью событий или простым указанием на неправдоподобие этого правдоподобия, и сами описанные при этом подрыве политики и техники распространения книг или почтения к книгам окажутся нормой для существования самих описывающих это книг. То же самое происходит и в романе Асса и Бегемотова: в их романе Штирлиц, умеющий правильно смоделировать размножение ежиков благодаря навыку овладевать незнакомыми кодировками, уничтожает культуру тела, созданную импотентом Гитлером, - и поневоле делает книжность, описывающую размножение ежиков и тем самым поощряющую сексуальную витальность, действительным будущим литературы: эротическое в постперестроечной литературе стало неотделимо от экспериментов с языком.

Анализируя роман, мы раскрыли шаг за шагом и общественный запрос на компьютерную технику как на преодолевающую косность старой аппаратуры и навязанной цензуры, мечту о компьютерах, которая мелькала в голове любого читателя этого фанфика, и то, как технические возможности компьютерной техники позволили Штирлицу стать из персонажа анекдотов идеальным пользователем-программистом. Программист Штирлиц и определил диапазон постперестроечной массовой литературы, сочетание приключенческого, эротического и экзотического элементов, которое не могло бы быть создано простой массовизацией совестской литературой, но оказалось эффектом нового медиа - компьютерного набора и свободного компьютерного редактирования для дальнейшего распространения, что было и экзотично на фоне старых издательских обычаев, но и привлекательно для всех новых читателей массовой литературы независимо от личных интересов.

\section{ЛИТЕРАТУРА}

Аверинцев Сергей. Поэтика ранневизантийской литературы. Москва: Наука, 1977 Александрова Елена. «Специфика создания языковой игры в анекдотах на русском языке». Русский язык и культура в зеркале перевода 1 (2014): 523-532. 
Арустамова Анна, Марков Александр. «Воспарение поэта: визуальные модели в прозе М. Булгакова». Артикульт 22/ 2 (2016): 110-121.

Архипова Александра. «Штирлии шел по коридору...»: Как мы придумываем анекдоты. Москва: РГГУ, 2013.

Асс Павел, Бегемотов Нестор. Штирлии, или как размножаются ежики. Роман. Авторский вариант. http://lib.ru/ANEKDOTY/shtirl-1.txt

Белоусов Александр. «Анекдоты о Штирлице». Живая старина 1 (1995): 16-18.

Дмитриев Анатолий. «Ю. Борев и интеллигентский фольклор». Социологические исследования 7 (1995): 138-141.

Домбровский Юрий. Хранитель древностей. Роман. Новелль. Эссе. Москва: Известия, 1991.

Рябова Галина. «Юмор и сатира на советской эстраде 1920-х гг.». Артикульт 3 (19) (2015): 51-60.

Спутницкая Нина. «Тенденции языка российской интернет-анимации: стереотипы национальной сказочной традиции и механизмы контркультурного дискурса». Артикульт 28/4 (2017): 101-106.

Степанова Мария. «О смерти и немного до». Коммерсант-Weekend 21 (2014): 36.

Эпштейн Михаил. Постмодернизм в России. Санкт-Петербург: Азбука-Аттикус, 2019.

\section{LITERATURE}

Averincev Sergej. Poetika rannevizantijskoj literatury. Moskva: Nauka, 1977

Aleksandrova Elena. «Specifika sozdaniya yazykovoj igry v anekdotah na russkom yazyke». Russkij yazyk i kul'tura $v$ zerkale perevoda 1 (2014): 523-532.

Arustamova Anna, Markov Aleksandr. «Vosparenie poeta: vizual'nye modeli v proze M. Bulgakova». Artikul't 22/ 2 (2016): 110-121.

Arhipova Aleksandra. «Shtirlic shel po koridoru...»: Kak my pridumyvaem anekdoty. Moskva: RGGU, 2013.

Ass Pavel, Begemotov Nestor. Shtirlic, ili kak razmnozhayutsya ezhiki. Roman. Avtorskij variant. http://lib.ru/ANEKDOTY/shtirl-1.txt

Belousov Aleksandr. «Anekdoty o Shtirlice». Zhivaya starina 1 (1995): 16-18.

Dmitriev Anatolij. «Yu. Borev i intelligentskij fol'klor». Sociologicheskie issledovaniya 7 (1995): 138-141.

Dombrovskij Yurij. Hranitel' drevnostej. Roman. Novelly. Esse. Moskva: Izvestiya, 1991.

Epshtejn Mihail. Postmodernizm v Rossii. Sankt-Peterburg: Azbuka-Attikus, 2019.

Ryabova Galina. «Yumor i satira na sovetskoj estrade 1920-h gg.». Artikul't 3 (19) (2015): 51-60.

Sputnickaya Nina. «Tendencii yazyka rossijskoj internet-animacii: stereotipy nacional'noj skazochnoj tradicii i mekhanizmy kontrkul'turnogo diskursa». Artikul't 28/4 (2017): 101-106.

Stepanova Mariya. «O smerti i nemnogo do». Kommersant-Weekend 21 (2014): 36.

Александар Марков

\section{САДРЖАЈНОСТ СМЕЊИВАҢА МЕДИЈСКЕ ФОРМЕ \\ У ПАРОДИЈСКОМ РОМАНУ ПАВЛА АСА И НЕСТОРА БЕГЕМОТОВА ШТИРЛИЦ, ИЛИ КАКО СЕ РАЗМНОЖАВАЈУ ЈЕЖИЋИ}

\section{Резиме}

На примеру пародијског циклуса романа о Штирлицу Павла Аса и Нестора Бегемотова показано је како је прелаз са дактилографског куцања и штампарског слагања слогова на компјутерско уношење текстова мењао тематске жеље читалаца. Развија се 
хипотеза о томе да је компјутерска размена текстова оспорила механизме производње текстова како у званичној књижевности, тако и у Самиздату. Званични систем производње текстова није подразумевао само цензуру него и одређену представу о високом степену свезнајућег аутора, који, захваљујући доступности како усменим, тако и писменим текстовима, може да усади читаоцу мисао о искључиво добрим намерама јунака. У пародијским романима о Штирлицу, који су постали бестселери у периоду између 1988. и 1994. године, тематизована је специфичност компјутерског кодирања и доступности информација, која је омогућила да коришћење компјутера прерасте из маргиналне праксе у предмет од општег интереса.

Кључне речи: интермедијалност, дигитално уношење текста, дигитално постојање текста, цензура, Самиздат, социологија масовног штива, Ото фон Штирлиц (Максим Исајев). 